\title{
Snare-Assisted Vascular Access: A New Technique
}

\author{
Collin G. Cowley, MD, Sarah Badran, MD, Albert P. Rocchini, MD, and Thomas R. Lloyd,* MD
}

\begin{abstract}
Access to the central circulation can be difficult in small infants, particularly when normal anatomic landmarks have been altered. We describe a new technique that utilizes any existing central catheter to establish additional sites of vascular access. A 4 Fr end hole catheter is advanced under fluoroscopic guidance to the desired site of new vascular access. A 10-mm Amplatz snare catheter is advanced through the end hole catheter and the loop opened within the target vessel lumen. The snare is then used to guide percutaneous placement of a Cope wire through a 21-gauge needle and then to pull the wire into the central circulation. New access is then achieved by introducing an additional catheter over the guidewire. This technique has now been successfully utilized 16 times in 13 patients. Snare assistance is a safe and effective technique that provides a reliable means of establishing additional secure vascular access. Cathet. Cardiovasc. Intervent. 47:315-318, 1999. - 1999 Wiley-Liss, Inc.
\end{abstract}

Key words: cardiac catheterization; congenital heart disease

\section{INTRODUCTION}

Reliable access to the central circulation in the pediatric population through desired specific sites of entry is often difficult or impossible using conventional techniques. Difficulty may stem from very small vessel size, hematoma formation, postoperative edema, or other deformities obscuring normal anatomic landmarks. Several groups of patients could potentially benefit from a technique to establish reliably intravascular access at desired sites using catheters at existing sites. Many critically ill patients have a continued need for arterial or central venous access following cardiac catheterization. Similarly, vascular access is occasionally desired at a specific site when other sites have already been established (e.g., right femoral vein for transeptal puncture, femoral vessels for balloon angioplasty, basilic veins for placement of peripherally inserted central catheters). There are also times when the need for intraoperative or postoperative central venous access can be anticipated in patients scheduled for surgery shortly after cardiac catheterization. We describe a new technique that is helpful in establishing additional intravascular access utilizing any existing central catheter.

\section{CASE REPORT}

Between February 1998 and October 1998, additional vascular access was established 16 times in 13 patients utilizing a newly developed technique. Discussion of the potential risks and benefits was undertaken. Informed consent was obtained from all patients prior to the procedure. All patients were monitored for subsequent complications through the Cardiac Catheterization Quality Assurance Program of the C.S. Mott Children's Hospital.

All procedures were performed using local anesthesia and conscious sedation. In the catheterization laboratory under single-plane fluoroscopic guidance, a $4 \mathrm{Fr}$ end hole catheter is advanced to the target vessel through any existing arterial or venous access. A 10-mm Amplatz gooseneck snare (Microvena Corporation, White Bear Lake, $\mathrm{MN}$ ) is then advanced through the catheter and the snare loop opened in the vessel lumen. A 21-gauge needle is then introduced percutaneously through the snare loop and into the soft tissues below the vessel (Fig. 1). Although single-plane fluoroscopy does not show the depth of needle penetration, initial contact of the needle with the adventitia alters the position of the snare, which returns to its previous position after the needle passes completely through the vessel. A 0.018 " diameter Cope wire (Cook, Bloomington, IN) is then advanced through the needle into the soft tissue below the vessel (Fig. 2). The needle is then withdrawn and the snare used to engage the wire, pulling it into the vessel lumen (Fig. 3). With the wire pulled into the central circulation and the Amplatz snare disengaged, the desired catheter or sheath can then be advanced over the wire into the vessel by the Seldinger technique.

Division of Pediatric Cardiology, University of Michigan, Ann Arbor, Michigan

*Correspondence to: Dr. Thomas R. Lloyd, F1310 MCHC Box 0204, 1500 E Medical Center Drive, University of Michigan, Ann Arbor, MI 48109. E-mail: 1loydt@umich.edu

Received 10 November 1998; Revision accepted 18 January 1999

(c) 1999 Wiley-Liss, Inc. 


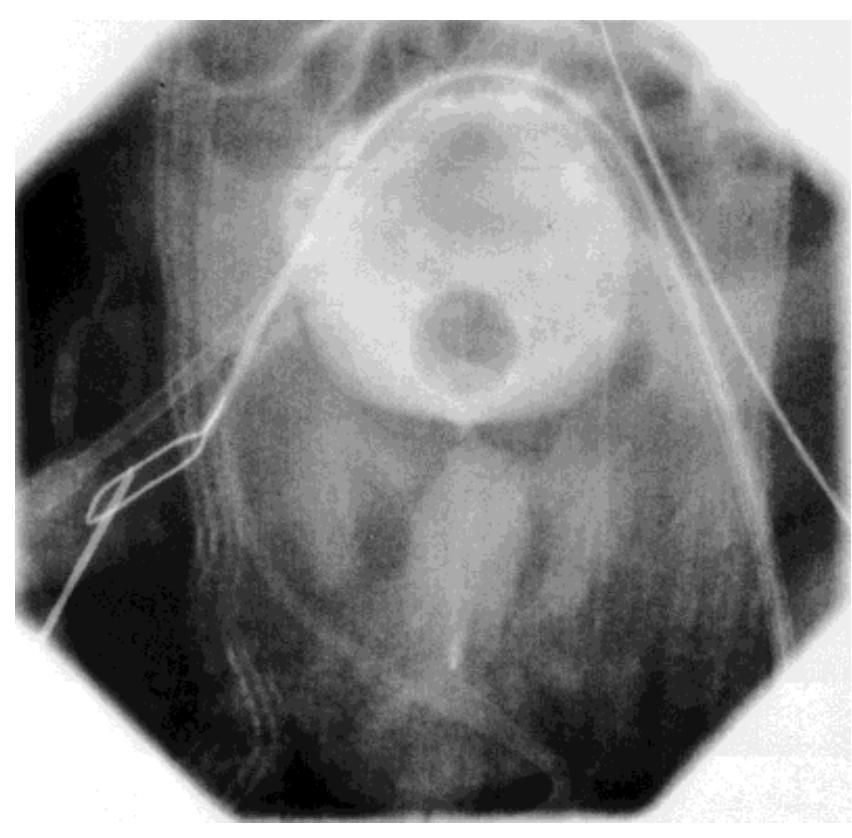

Fig. 1. An Amplatz snare catheter is positioned in the right femoral vein from the left femoral vein with the snare loop open providing a target for percutaneous introduction of a needle. A 21-gauge needle is introduced through the snare loop into the soft tissues below the vessel. Also visible are a sheath in the right femoral artery and a left femoral artery catheter that was placed by the snare technique.

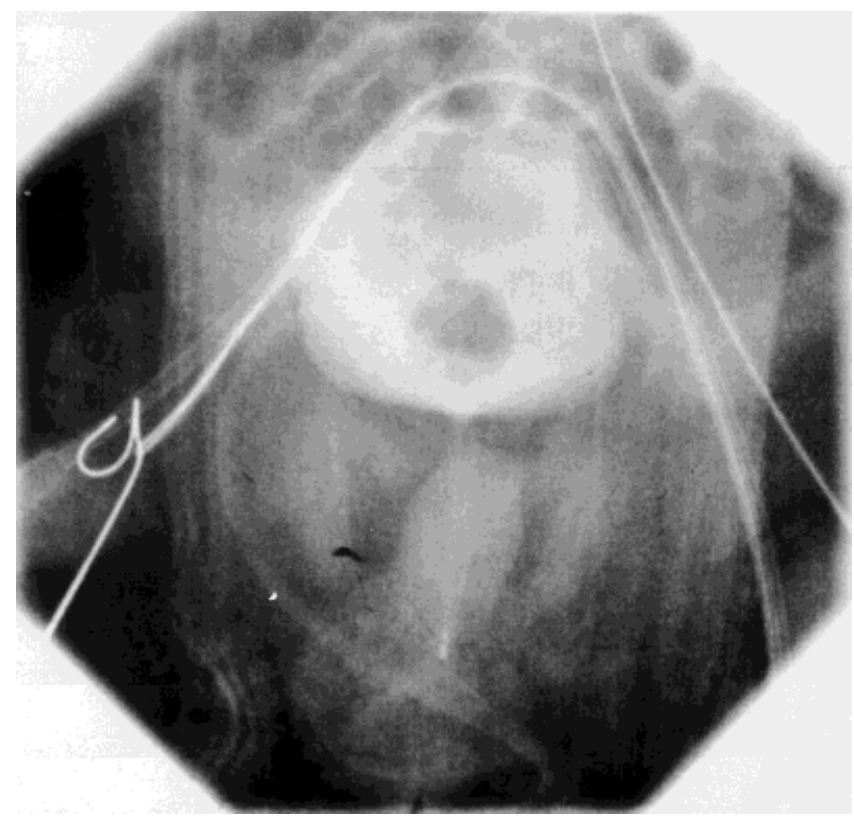

Fig. 2. The snare loop is used to engage the soft tip of the Cope wire and to pull it into the vessel lumen.

\section{RESULTS}

Table I summarizes the patient age and weight, the clinical setting, indication for the procedure, the sites of vascular access utilized to establish additional sites of

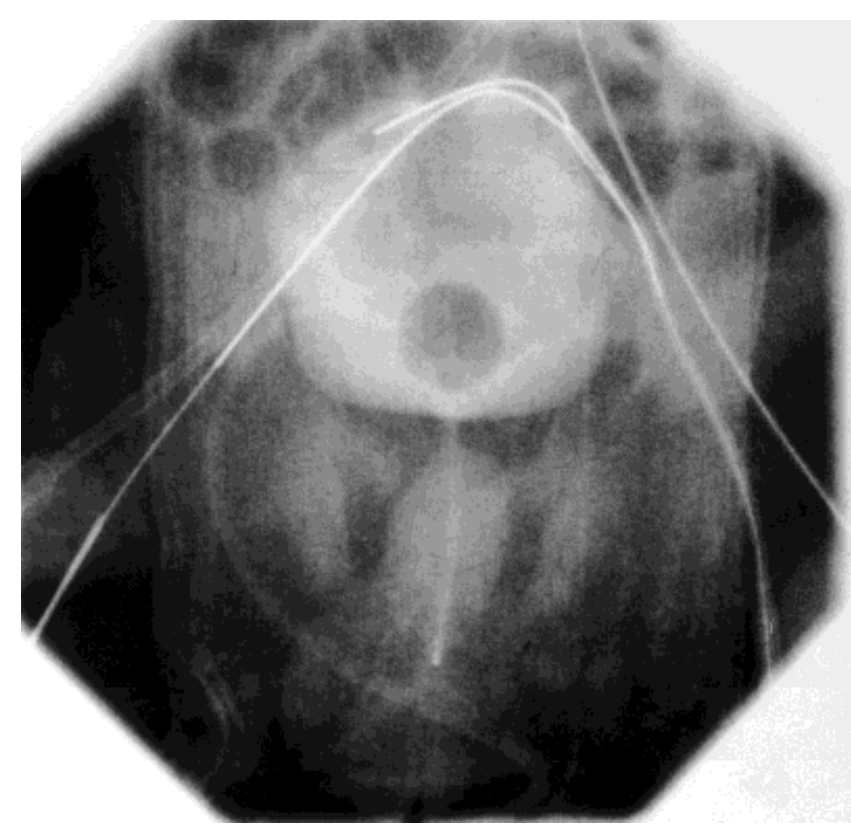

Fig. 3. The snare is used to pull the wire well into the vessel or central circulation. A catheter can then be passed over the wire using conventional techniques.

vascular access, and the procedure and fluoroscopy exposure times. The median patient age was 83 days ( 8 days -17 years). The median patient weight was $4.5 \mathrm{~kg}$ $(2.7-40.0 \mathrm{~kg})$. Five of 16 procedures were performed specifically for placement of peripherally inserted central catheters. In four of these patients (ages 25 days-9 weeks), the snare technique was the only access method used. Procedure time averaged $91 \mathrm{~min}(75-117 \mathrm{~min})$, requiring an average of $14.2 \mathrm{~min}(11.7-17.9 \mathrm{~min})$ of fluoroscopy exposure. The fifth patient (age 9 years), with no existing central access, first had unsuccessful attempts at vascular access using venographic guidance [1], resulting in hematoma and venous spasm. Percutaneous femoral venous access was then obtained and the snare advanced into the spasmed vein. After snare-assisted placement of the peripherally inserted central catheter, the femoral sheath was removed. This procedure in total lasted $128 \mathrm{~min}$ and required $31.9 \mathrm{~min}$ of fluoroscopy exposure. Procedure times include the time required to transfer patients to and from the catheterization table. There were no complications from these procedures. Specifically no paralysis, limb ischemia, venous obstruction, or formation of new, clinically significant hematoma was observed.

\section{DISCUSSION}

We have described a safe and reliable method for establishing vascular access using snare assistance. The most distinctive feature of this technique is that the needle 
TABLE I. Details of 16 Procedures Involving 13 Patients

\begin{tabular}{|c|c|c|c|c|c|c|c|c|c|}
\hline $\begin{array}{l}\text { Pro- } \\
\text { cedure }\end{array}$ & Patient & Age & $\begin{array}{l}\text { Weight } \\
(\mathrm{kg})\end{array}$ & Clinical setting & Indication & Existing access & Snare site & $\begin{array}{l}\text { Procedure } \\
\text { time } \\
(\mathrm{min})\end{array}$ & $\begin{array}{l}\text { Fluoro } \\
\text { time } \\
(\mathrm{min})\end{array}$ \\
\hline 1 & 1 & 8 days & 4.7 & $\begin{array}{l}\text { s/p Arterial switch } \\
\text { operation }\end{array}$ & Central catheter & Left femoral vein & $\begin{array}{l}\text { Right internal } \\
\text { jugular vein }\end{array}$ & & \\
\hline 2 & 1 & 25 days & 3.9 & $\begin{array}{l}\text { s/p Arterial switch } \\
\text { operation }\end{array}$ & $\begin{array}{l}\text { Peripherally inserted } \\
\text { central catheter }\end{array}$ & Transhepatic & Left basilic & 87 & 11.7 \\
\hline 3 & 2 & 2 months & 2.7 & s/p Norwood, Rastelli & $\begin{array}{l}\text { Peripherally inserted } \\
\text { central catheter }\end{array}$ & Left subclavian & Right basilic & 75 & 13.2 \\
\hline 4 & 3 & 11 days & 3.1 & $\begin{array}{l}\text { s/p central shunt (emer- } \\
\text { gent catherization) }\end{array}$ & Postcatherization access & Left femoral vein & Right femoral vein & & \\
\hline 5 & 3 & 11 days & 3.1 & $\begin{array}{l}\text { s/p central shunt (emer- } \\
\text { gent catherization) }\end{array}$ & Postcatherization access & Right femoral artery & Left femoral artery & & \\
\hline 6 & 4 & 3 months & 2.9 & $\begin{array}{l}\text { s/p Arterial switch } \\
\text { operation }\end{array}$ & $\begin{array}{l}\text { Preballoon valvulo- } \\
\text { plasty }\end{array}$ & $\begin{array}{l}\text { Right internal jugular } \\
\text { vein }\end{array}$ & Left femoral vein & & \\
\hline 7 & 5 & 21 months & 10.4 & $\begin{array}{l}\text { Hypoplastic left heart } \\
\text { syndrome, pre- } \\
\text { Fontan }\end{array}$ & $\begin{array}{l}\text { Peripherally inserted } \\
\text { central catheter }\end{array}$ & Right subclavian & Left basilic & & \\
\hline 8 & 6 & 5 weeks & 4.0 & $\begin{array}{l}\text { s/p Arterial switch } \\
\text { operation, arch } \\
\text { reconstruction }\end{array}$ & $\begin{array}{l}\text { Peripherally inserted } \\
\text { central catheter }\end{array}$ & Right femoral vein & Right basilic & & \\
\hline 9 & 6 & 9 weeks & 4.3 & $\begin{array}{l}\text { s/p Arterial switch } \\
\text { operation, arch } \\
\text { reconstruction }\end{array}$ & $\begin{array}{l}\text { Peripherally inserted } \\
\text { central catheter }\end{array}$ & Right femoral vein & Right basilic & 85 & 14.1 \\
\hline 10 & 7 & 5 weeks & 3.4 & $\begin{array}{l}\text { Tetralogy of Fallot, } \\
\text { absent pulmonary } \\
\text { valve s/p repair }\end{array}$ & $\begin{array}{l}\text { Peripherally inserted } \\
\text { central catheter }\end{array}$ & Right femoral vein & Left basilic & 117 & 17.9 \\
\hline 11 & 8 & 5 months & 5.6 & $\begin{array}{l}\text { L-transposition of the } \\
\text { great arteries } \mathrm{s} / \mathrm{p} \\
\text { hemi-Fontan }\end{array}$ & $\begin{array}{l}\text { Peripherally inserted } \\
\text { central catheter }\end{array}$ & Right femoral vein & Left basilic & & \\
\hline 12 & 9 & 6 years & 18.5 & $\begin{array}{l}\text { Cardiomyopathy, pre- } \\
\text { transplant }\end{array}$ & $\begin{array}{l}\text { Peripherally inserted } \\
\text { central catheter }\end{array}$ & Right femoral vein & Right basilic & & \\
\hline 13 & 10 & 17 years & 40 & s/p Transplant & Postcatherization access & Right femoral artery & Left femoral artery & & \\
\hline 14 & 11 & 9 years & 31 & $\begin{array}{l}\text { Subacute bacterial } \\
\text { endocarditis }\end{array}$ & $\begin{array}{l}\text { Peripherally inserted } \\
\text { central catheter }\end{array}$ & Right femoral vein & Right basilic & 128 & 31.9 \\
\hline 15 & 12 & 2 years & 11.1 & $\begin{array}{l}\text { Pulmonary atresia, } \\
\text { intact ventricular } \\
\text { septum pre-Fontan }\end{array}$ & $\begin{array}{l}\text { Peripherally inserted } \\
\text { central catheter }\end{array}$ & Right subclavian & Left basilic & & \\
\hline 16 & 13 & 19 months & 10.6 & $\begin{array}{l}\text { Tricuspid atresia, pre- } \\
\text { Fontan }\end{array}$ & $\begin{array}{l}\text { Peripherally inserted } \\
\text { central catheter }\end{array}$ & Right subclavian & Left basilic & & \\
\hline
\end{tabular}

and guidewire are both intentionally passed through opposing walls of the target vessel. The snare essentially guarantees that the guidewire will achieve the desired position within the vessel lumen. In contrast, traditional landmark methods, such as fluoroscopic methods using venography [1], or a catheter or guidewire target [2,3], or ultrasound techniques using imaging or Doppler [4,5], require positioning of the needle tip within the lumen in order for guidewire passage to occur. This difference is especially important in uncooperative pediatric patients and in small infants whose vessels are often little or no larger than the 21-gauge introducer needle. Not only does the snare technique relieve the operator of the burden of perfect needle placement, but the snare itself stents spasmed vessels open and stretches small vessels, presenting a larger target to the operator.

Multiple attempts at vessel puncture can result in vessel spasm, hematoma, and injury to adjacent struc- tures, especially arteries and nerves. In our experience, the target provided by the snare is far superior to that provided by a catheter, wire, venography, or ultrasound, especially in small vessels. We therefore expect that fewer puncture attempts would be necessary. Puncturing both walls of the vessel is tolerated because of the use of a very fine needle and guidewire. We therefore speculate that this technique may be particularly advantageous in patients with impaired coagulation.

The basilic vein is smaller than the central veins and much more mobile, making access for peripherally inserted central catheters the most technically demanding use of the snare technique in our study. Nevertheless, we were able to place catheters in all 11 patients attempted despite our generally small and uncooperative patient population. The procedure and fluoroscopic exposure times reported are comparable to our experience in infants and children using venographic visualization of 
the basilic vein. Our experience shows that even spasmed veins that might not be imaged by venography or ultrasound can be cannulated using the snare-assisted technique.

Our experience to date has led us to prefer certain catheters and wires for navigating specific intravascular courses. The use of an angled Glidewire (Meditech, Boston Scientific, Watertown, MA) simplifies retrograde access to the basilic veins. A 4 Fr Judkins (Cordis, Miami, FL) right coronary artery catheter facilitates traversing from either subclavian vein to the contralateral basilic vein. Similarly, the use of a 0.035 " J-wire through a $4 \mathrm{Fr}$ Judkins left coronary artery catheter allows passage across the acute angle encountered in crossing from femoral to contralateral femoral vessel.

The primary limitation of this technique is the need for existing vascular access with vascular continuity between existing and desired sites of vascular access. Discontinuity can be congenital (e.g., persistent left superior vena cava), acquired (e.g., vessel occlusion), or surgical (e.g., Glenn anastomosis) in nature. In addition, if existing catheters are felt to be infected, they are unlikely to be suitable for use in establishing additional vascular access using this technique. Patients are also exposed to ionizing radiation, which could be avoided by using ultrasound guidance in suitable patients [4-7]. For patients who do not require cardiac catheterization, bedside techniques avoid the risks, inconveniences, and expense of transportation to and from and use of the catheterization labora- tory. Bedside techniques were not considered appropriate for patients in this study.

Despite these limitations, snare-assisted vascular access has proved a valuable adjunct to conventional methods of establishing vascular access in patients of all ages and sizes. The high success rate and the lack of complications make this approach particularly valuable as a means of establishing additional vascular access at specific sites of entry when conventional methods are unsuccessful.

\section{REFERENCES}

1. Cardella JF, Fox PS, Lawler JB. Interventional radiologic placement of peripherally inserted central catheters. J Vasc Interv Radiol 1993;4:653-660.

2. Chandrasekar B, Abraham KA. Severe spasm of subclavian vein: cannulation by a new technique. J Invas Cardiol 1998;10:346348.

3. Harris GA Jr, Carell ES. Placement of peripherally inserted catheters in the catheterization laboratory. Cathet Cardiovasc Diagn 1997;41:189-191.

4. Denys BG, Uretsky BF, Reddy PS, Ruffner RJ, Sandhu JS, Breishlatt WM. An ultrasound method for safe and rapid central venous access. N Engl J Med 1991;324:566.

5. Machi J, Takeda J, Kakegawa T. Safe jugular and subclavian venipuncture under ultrasonographic guidance. Am J Surg 1987;154: 321-323.

6. Branger B, Dauzat M, Zabadani B, Vecina F, Lefranc JY. Pulsed Doppler sonography for the guidance of vein puncture: a prospective study. Artif Organs 1995;19:93-98.

7. Caridi JG, Hawkins IF Jr, Wiechman BN, Pevarski DJ, Tonkin JC. Sonographic guidance when using the right internal jugular vein for central vein access. Am J Roentgenol 1998;171:1259-1263. 